\title{
Exploring beliefs on diabetes treatment adherence among Dutch type 2 diabetes patients and healthcare providers
}

Citation for published version (APA):

Vluggen, S., Hoving, C., Schaper, N. C., \& de Vries, H. (2018). Exploring beliefs on diabetes treatment adherence among Dutch type 2 diabetes patients and healthcare providers. Patient Education and Counseling, 101(1), 92-98. https://doi.org/10.1016/j.pec.2017.07.009

Document status and date:

Published: 01/01/2018

DOI:

10.1016/j.pec.2017.07.009

Document Version:

Publisher's PDF, also known as Version of record

Document license:

Taverne

Please check the document version of this publication:

- A submitted manuscript is the version of the article upon submission and before peer-review. There can be important differences between the submitted version and the official published version of record.

People interested in the research are advised to contact the author for the final version of the publication, or visit the DOI to the publisher's website.

- The final author version and the galley proof are versions of the publication after peer review.

- The final published version features the final layout of the paper including the volume, issue and page numbers.

Link to publication

\footnotetext{
General rights rights.

- You may freely distribute the URL identifying the publication in the public portal. please follow below link for the End User Agreement:

www.umlib.nl/taverne-license

Take down policy

If you believe that this document breaches copyright please contact us at:

repository@maastrichtuniversity.nl

providing details and we will investigate your claim.
}

Copyright and moral rights for the publications made accessible in the public portal are retained by the authors and/or other copyright owners and it is a condition of accessing publications that users recognise and abide by the legal requirements associated with these

- Users may download and print one copy of any publication from the public portal for the purpose of private study or research.

- You may not further distribute the material or use it for any profit-making activity or commercial gain

If the publication is distributed under the terms of Article $25 \mathrm{fa}$ of the Dutch Copyright Act, indicated by the "Taverne" license above, 
Health Care and Health Promotion

\title{
Exploring beliefs on diabetes treatment adherence among Dutch type 2 diabetes patients and healthcare providers
}

\author{
S. Vluggen ${ }^{\mathrm{a}, *}$, C. Hoving ${ }^{\mathrm{a}}$, N.C. Schaper ${ }^{\mathrm{b}}$, H. de Vries ${ }^{\mathrm{a}}$ \\ a Department of Health Promotion, Maastricht University, Maastricht, The Netherlands \\ ${ }^{\mathrm{b}}$ Department of Endocrinology and Internal Medicine, Maastricht University Medical Centre (MUMC+), Maastricht, The Netherlands
}

\section{A R T I C L E I N F O}

\section{Article history:}

Received 22 January 2017

Received in revised form 21 June 2017

Accepted 8 July 2017

\section{Keywords:}

Type 2 diabetes

Treatment adherence

Healthy lifestyle

Pharmacotherapy

Patients

Healthcare providers

Consultations

Personal beliefs

\begin{abstract}
A B S T R A C T
Objective: Despite well-known beneficial effects, adherence to core elements of diabetes treatment is suboptimal. This study, conducted in the Netherlands, aimed to explore if and how treatment adherence success factors are applied in diabetes consultations, and to explore salient personal beliefs about type 2 diabetes treatment including both healthy lifestyle adaptations and pharmacotherapy.

Methods: A qualitative study using semi-structured interviews among nine Dutch healthcare providers predominantly involved in diabetes management and 19 Dutch type 2 diabetes patients. Data was systematically analysed through deductive coding analysis using Nvivo.

Results: Most patients visited their consultations unprepared. Patients did not or vaguely experience goalsetting in consultations, whereas healthcare providers indicated to set treatment goals. Shared-decision making was applied, however patients were rather passive collaborators as mostly healthcare providers were in charge of making treatment decisions. Despite suboptimal treatment adherence, many advantages and few disadvantages of treatment strategies were reported. Adherence self-efficacy was lower in situations outside daily routine.

Conclusion: Treatment adherence success factors are not optimally applied, and in particular treatment adherence self-efficacy could be improved.

Practice implications: The application of treatment adherence success factors in consultations could be improved, and personal beliefs should be addressed to improve treatment adherence and optimize counselling.
\end{abstract}

(c) 2017 Elsevier B.V. All rights reserved.

\section{Introduction}

Type 2 diabetes mellitus (T2DM) is a chronic progressive disease characterized by hyperglycaemia and the body's inability to retain an optimal glucose metabolism [1,2]. Worldwide nearly 400 million people live with T2DM, with expectations of almost 600 million people being affected by 2035 [2]. This rise is largely attributable to unhealthy energy balance-related behaviours such as physical inactivity and unhealthy dietary patterns [1-3]. Core T2DM treatment elements, which target an optimal glucose metabolism, consist of adaptations towards healthy lifestyles, i.e. increasing physical activity (PA) and improving dietary

\footnotetext{
* Corresponding author at: Maastricht University, Department of Health Promotion, CAPHRI, Care and Public Health Research Institute, Room B1.105, P. Debyeplein 1, 6229 HA Maastricht, The Netherlands.

E-mail addresses: stan.vluggen@maastrichtuniversity.nl (S. Vluggen),

c.hoving@maastrichtuniversity.nl (C. Hoving),n.schaper@mumc.nl (N.C. Schaper), hein.devries@maastrichtuniversity.nl (H. de Vries).
}

patterns, and pharmacotherapy, i.e. taking glucose lowering pills and/or injecting insulin [4]. Despite the well-known long-term benefits of adequate glycaemic control on reducing microvascular complications and death from any cause [5], patients' treatment adherence is suboptimal [6-8]. Several studies show that the majority of T2DM patients does not meet recommended levels of PA and does not adhere to dietary guidelines [9,10]. Moreover, King et al. [11] showed that over $95 \%$ of diabetes patients failed to adhere to all five healthy lifestyle recommendations studied. Adherence prevalences on diabetes pharmacotherapy vary across studies from 38.5 to $93.1 \%$, far most of them reporting prevalences $<80 \%$ [12]. Poor adherence not only impedes beneficial treatment effects, but is also associated with disease worsening, cardiovascular risks, a reduced quality of life, more hospitalizations, increased healthcare costs, and premature mortality [13-19].

Treatment adherence implies collaboration between a healthcare provider (HCP) and a patient in the formulation and agreement of treatment strategies. This collaborative care strategy can be applied in consultations, which should serve as a setting 
where patients are informed, educated, facilitated, motivated, and taught skills to optimally self-manage T2DM in daily life [20]. Determinants of patient treatment adherence have been identified at both HCP and patient level. At the HCP level, knowledge insufficiencies, lack of time and motivation, and difficulties in involving patients in decision-making have been identified as adherence barriers [21]. Patients on the other hand often lack knowledge and motivation to change lifestyles, and discipline to persist adapted lifestyles [21-23]. Moreover, French et al. [24] demonstrate that personal beliefs about treatment play an important role in treatment adherence, especially regarding the core elements of T2DM treatment. To ensure treatment success and adequate glycaemic control, active patient engagement, applying goal setting principles, tailoring treatment strategies to patients' needs, beliefs and abilities, involving patients in decisionmaking, and effective ongoing self-management beyond consultations is required $[14,22,25,26]$. Because the basis for treatment strategies originates from consultations between HCPs and patients, and as still many patients suboptimally adhere to their treatment, it is evident to profoundly explore if and how treatment adherence success factors are applied in consultations. Moreover, it is important to explore salient personal beliefs about core treatment elements as they play an important role in treatment adherence. A better understanding of these factors can offer handles to optimize treatment adherence and improve T2DM counselling [24].

The aim of this study was to: (1) explore if and how treatment adherence success factors are applied in consultations between HCPs and T2DM patients, and (2) explore salient personal beliefs about T2DM treatment, including both healthy lifestyle adaptations and pharmacotherapy among HCPs and T2DM patients.

\section{Methods}

\subsection{Procedure}

We conducted a qualitative study using semi-structured individual interviews among HCPs predominantly involved in T2DM management and T2DM patients. The study was approved by the ethics committee of the MUMC+ (15-4-094).
HCPs and patients were recruited from July up to November 2015 in the southern region of the Netherlands. Purposefully efforts were made to recruit a heterogeneous sample in terms of age, gender, education level, and healthcare setting. A priori, we aimed to conduct 25 interviews among fifteen T2DM patients and ten HCPs: our initial analysis sample [27]. This number was chosen because both perspectives needed to yield sufficient representative results. We aimed to include more patients, as the absolute number of patients is much larger than the actual number of HCPs. Moreover we thought that HCPs would carry many experiences of consultations with patients, whereas patients would only have their own experience. After these 25 initial interviews, two additional patient interviews and one additional professional interview were conducted to confirm saturation and content validity for both interviewed groups [27]. No new themes emerged from these additional interviews, hence data saturation was reached. The inclusion criterion for HCPs was: having treated T2DM patients in the Netherlands at least once in the last three months. Further we included general practitioners, practice nurses, internists, diabetes nurses, and dieticians. In the Netherlands, these professionals are predominantly involved in T2DM management and in shaping treatment strategies, hence these HCPs were included [23]. HCPs were recruited through email, including a non-committal study description and a participation request. In case of participation agreement, an interview date was picked, and HCPs provided written informed consent. HCPs were interviewed by the first author at the HCPs' workplace. Afterwards, they received a symbolic diabetes-related reward. Five general practices and one hospital were approached to recruit patients. Eligible patients were identified by the HCP and inclusion criteria were: T2DM diagnosis for at least one year, 40-70 years old, receiving treatment in the Netherlands, and using at least one form of glucose lowering medication. Patients not able to speak and understand the Dutch language and patients unable to use a computer were excluded. Eligible patients were approached by their HCP to explain study details, including a non-committal information letter with a study description, and a participation request. In case of willingness to participate, $s /$ he could contact the researcher, an interview date was picked, and patients provided written informed consent.

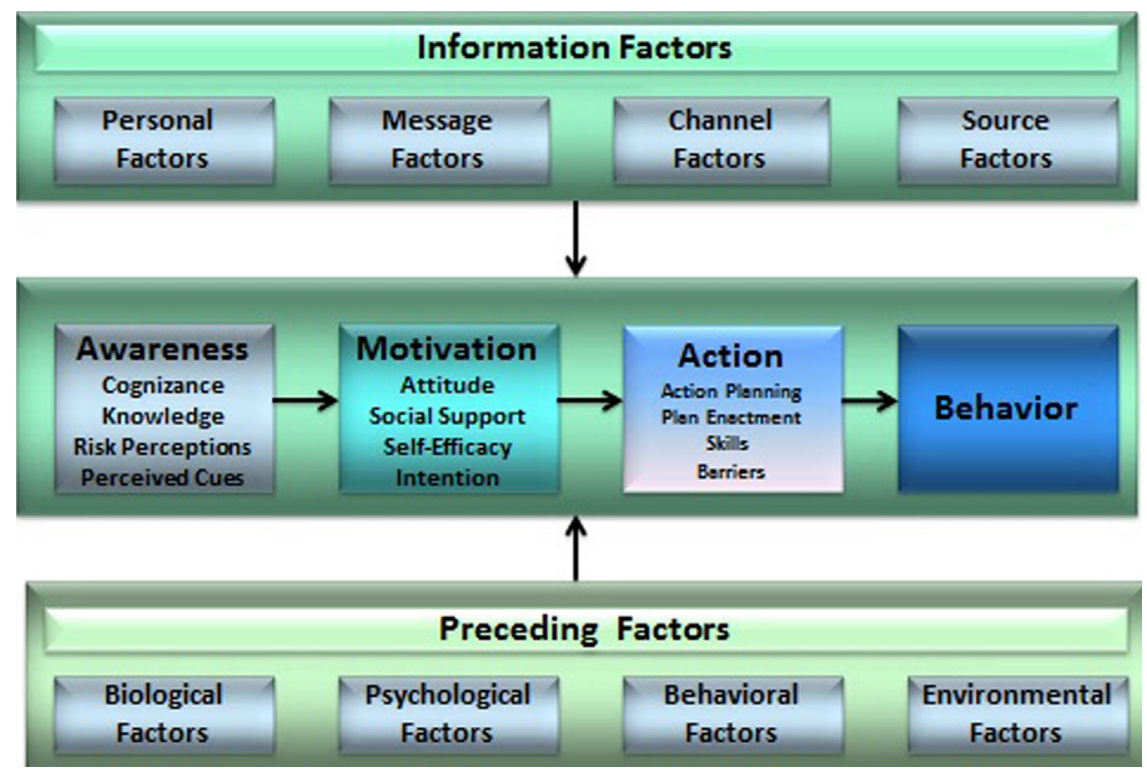

Fig. 1. The I-Change Model. 
Patients were interviewed at the research institute by the first author and rewarded with a $€ 25$,- gift card.

\subsection{Measurement}

All interviews were structured using an interview route. Various experts involved in T2DM management and T2DM patients provided feedback on the interview route and adaptations were made resulting in a final version consisting of four topics: consultations between HCPs and patients, salient personal beliefs about T2DM treatment, diabetes literacy, and eHealth. Diabetes literacy and eHealth are not further elaborated in this manuscript. Interviews started with identifying demographic characteristics. The I-Change Model (Fig. 1) [28] was used to theoretically inform this study. The model distinguishes an awareness, motivation, and action phase in explaining and changing behaviour, which are influenced by preceding and information factors. It incorporates various socio-cognitive theories [29-31] and has been used frequently to identify beliefs involved in health-related behaviour [32]. Consultations between HCPs and patients focussed on treatment adherence success factors such as goal-setting, shared-decision making (SDM), and self-management (education). These factors fall under 'information factors' in the I-Change Model [28]. Moreover, the I-Change Model incorporates several determinants of treatment adherence which have been identified earlier like knowledge, attitudes, self-efficacy, and action planning [2123]. These determinants were operationalized (Table 1 ) to identify underlying salient personal beliefs of core treatment elements. The identification of these beliefs focussed mainly on determinants in the awareness and motivation phase.

\subsection{Analysis}

Interviews were audio recorded, transcribed verbatim, anonymized, and analysed using Nvivo 10 [33]. Deductive coding analysis [34] was performed by two researchers; the first author and a research assistant. For HCPs and patients separately, a pre-defined coding tree was independently applied to a single random transcript by both researchers. Interview passages were assigned codes, and the creation of additional codes and inconsistencies were discussed and agreed upon. The same process was then repeated on three other random transcripts. This resulted in a final coding tree which was then applied to analyse four random HCPs transcripts and four patients' transcripts by both researchers [34]. Subsequently, the intercoder reliability and Cohen's Kappa were assessed using the coding comparison query. For both HCPs and patients, this resulted in a percent agreement of 0.99 , reflecting a high degree to which interview passages were assigned to the same codes by both researchers. The Cohen's Kappa showed to be 0.67 for the HCPs group and 0.79 for the patients group, reflecting a good strength of intercoder agreement [34,35].

\section{Results}

\subsection{Sample characteristics}

Thirty-one participants agreed on study participation: nine HCPs and 22 patients. Three patients were excluded because they did not meet the inclusion criteria. Five interviews were conducted in two parts because of time constraints of participants. HCP interviews were conducted with general practitioners $(\mathrm{GP}, \mathrm{N}=2)$, practice nurses ( $\mathrm{PN}, \mathrm{N}=2$ ), internists (INT, $\mathrm{N}=1$ ), diabetes nurses (DN, $\mathrm{N}=2$ ), and dieticians (DIET, $\mathrm{N}=2$ ). Interviews with HCPs lasted on average $61 \mathrm{~min}$, ranging from 50 to $75 \mathrm{~min}$. Interviews with patients lasted on average $82 \mathrm{~min}$, ranging from 59 to $107 \mathrm{~min}$. Patients had on average a suboptimal HbA1c-level of $63 \mathrm{mmol} / \mathrm{mol}$, and were on average obese $\left(\mathrm{BMI}=35.4 \mathrm{~kg} / \mathrm{m}^{2}\right)$. Sample characteristics are shown in Table 2.

\subsection{Diabetes consultations}

\subsubsection{Course and content}

Most patients indicated to visit their practice nurse or diabetes nurse quarterly, their general practitioner or internist once a year, and a dietician if appropriate. All HCPs reported that the course and content of those consultations was highly protocolled, meaning that several topics like discussing blood tests results, lifestyle and medication (adherence), and complication management would recur every consultation. Moreover, if applicable, time was devoted to issues raised by patients like questions and personal demands of care. Little time was spent on self-management education [Quote \#1]. Most HCPs and patients reported that patients did not prepare their consultations. Patients who did so, reported activities such as recording blood glucose levels and writing down questions. HCPs stated that they would welcome a more active participation and disease engagement of their patients, as many were passively

Table 1

Interview questions: operationalization I-Change Model concepts.

\begin{tabular}{|c|c|}
\hline I-Change Model Concept & Operationalization \\
\hline \multirow[t]{4}{*}{ Information Factors } & What is the course and content of a consultation meeting? \\
\hline & Do patients prepare their consultation, and how? \\
\hline & Are treatment strategies and goals formulated, and how? \\
\hline & What is the role of the patient and HCP in a consultation, and (how) is shared-decision making applied? \\
\hline Perceived Cues & What is a direct trigger for you to be physically active? \\
\hline Cognizance & Do you (think) you adhere to your medication regimen? \\
\hline \multirow{2}{*}{ Knowledge } & What is the effect/mode of action of your medication? \\
\hline & Which are (un)healthy foods? \\
\hline \multirow[t]{2}{*}{ Risk Perceptions } & What could happen if you don't use your medication, and how severe would you find this? \\
\hline & What could be consequences of being physically inactive, and how severe would you find this? \\
\hline \multirow[t]{2}{*}{ Attitudes } & What are advantages for you of a healthy diet? \\
\hline & What are disadvantages for you of being physically active? \\
\hline \multirow[t]{2}{*}{ Social Influences } & Who supports you to use your medication? \\
\hline & Are there people who think you should eat healthy? \\
\hline Self-efficacy & In which situations is it more difficult for you to be physically active? \\
\hline Intention & Are you planning on improving your medication adherence? \\
\hline Action Planning & Which plans do you have to increase your physical activity? \\
\hline Coping Planning & Which coping plans do you have to eat healthier when facing a difficult situation? \\
\hline
\end{tabular}


Table 2

Sample characteristics interviewees.

\begin{tabular}{|c|c|c|}
\hline & $\mathrm{N}(\%)$ & Mean (SD) \\
\hline \multicolumn{3}{|l|}{ T2DM Patient Characteristics } \\
\hline \multicolumn{3}{|l|}{ Gender } \\
\hline Male & $10(52.6)$ & \\
\hline Female & $9(47.4)$ & \\
\hline \multicolumn{3}{|l|}{ Education level } \\
\hline High & $6(31.6)$ & \\
\hline Low & $13(68.4)$ & \\
\hline \multicolumn{3}{|l|}{ Marital Status } \\
\hline Single & $4(21.1)$ & \\
\hline In a relationship & $15(78.9)$ & \\
\hline \multicolumn{3}{|l|}{ Pharmacotherapy } \\
\hline Glucose lowering pills & $6(31.6)$ & \\
\hline Insulin & $3(15.8)$ & \\
\hline Combined & $10(52.6)$ & \\
\hline Age & & $57.3(7.1)$ \\
\hline $\mathrm{HbA}_{1 \mathrm{c}}(\mathrm{mmol} / \mathrm{mol})^{\mathrm{a} / \mathrm{b}}$ & & $63^{\mathrm{a}}(18.1)$ \\
\hline BMI $\left(\mathrm{kg} / \mathrm{m}^{2}\right)^{\mathrm{b}}$ & & $35.4(6.7)$ \\
\hline T2DM Duration (years) & & $12.7(8.6)$ \\
\hline Interview Duration (min.) & & $82(17.3)$ \\
\hline \multicolumn{3}{|l|}{ HCPs' Characteristics } \\
\hline \multicolumn{3}{|l|}{ Gender } \\
\hline Male & $3(33.3)$ & \\
\hline Female & $6(66.7)$ & \\
\hline \multicolumn{3}{|l|}{ Work Setting } \\
\hline Primary Healthcare & $5(55.6)$ & \\
\hline Secondary Healthcare & $4(44.4)$ & \\
\hline Age & & $47.3(11.4)$ \\
\hline Interview Duration (min.) & & $60.6(7.8)$ \\
\hline
\end{tabular}

oriented. Few HCPs actually tried to stimulate their patients to actively participate [Quote \#2].

\subsubsection{Goal setting}

Most patients indicated that no goals were set regarding treatment strategies. Patients reported that if goals were set, they were often vague and perceived as advice rather than goals [Quote \#3]. In contrast to patients' perceptions, most HCPs reported that they often formulated goals during consultations, especially concerning lifestyle changes, improving glycemic control and treatment adherence, and stabilizing disease worsening. Most HCPs indicated to tailor goals to patients' needs and abilities by proposing small steps and realistic goals [Quote \#4]. Some HCPs reported that treatment goals were often not reached due to a lack of motivation in patients. According to some HCPs, patients sometimes aimed for higher, unachievable goals [Quote \#5].

\subsubsection{Shared-decision making}

A small majority of HCPs and patients indicated that the course and content of consultations, as well as the formulation of treatment strategies and goals, were determined by the HCP and patient in conjunction. This manifested itself either in patients who passively agreed on subjects and treatment strategies proposed by their HCP, justified by 'the HCP knows best', or through a few patients who came up with treatment ideas themselves. HCPs perceived that older patients were more dependent on the HCP's approach and younger patients were seen as more active collaborators through bringing up treatment ideas themselves and searching information on the Internet [Quotes \#6 and \#7]. Many HCPs indicated that treatment adherence was the patient' own responsibility. Contrary to the overall passive engagement in the formulation of treatment strategies, all patients felt they were responsible for treatment adherence.

\subsection{Adherence to treatment elements}

Many patients stated to be physically active and only few stated to be fully inactive. Often mentioned activities which contributed to PA were: walking (the dog/upstairs), cycling, shopping, household activities, and visiting a physiotherapist or gym. However, according to almost all HCPs, adherence to PA guidelines was poor [Quote \#8]. According to most HCPs, adherence to healthy diets was poor. Issues identified focused on irregularity of meals, portion size and snacking in between and/or after regular meals. In general, patients indicated to maintain a healthy diet. However, when asking for detailed diet description, emphatically intense savory and sugary snacking behavior in between or after regular meals could be identified in most patients [Quotes \#9 and \#10]. Near all HCPs reported that adherence to pharmacotherapy in patients was suboptimal. Both intentional (purposely skipping or altering regimes) and unintentional (forgetting) non-adherence underlie this statement. Half of the patients indicated to always adhere to their diabetes pharmacotherapy. Regarding adherence to glucose lowering pills and insulin, similar types of non-adherence emerged like forgetting, skipping, stopping, stacking medication, adapting dosages, and using medication at varying times [Quotes \#11 and \#12].

\subsection{Awareness beliefs}

HCPs believed that patients' knowledge levels regarding health benefits of PA were sufficient. Almost all patients believed that regular PA should be part of a healthy lifestyle. When discussing risks of PA non-adherence, patients stated risk of weight gain, loss of fitness, becoming less mobile, getting hyperglycemia, and developing cardiovascular diseases [Quote \#13]. Regarding a healthy diet, HCPs indicated that patients were aware of the fact that they should eat less and healthier, but that they were less aware of the products which did and did not contain carbohydrates. Furthermore, HCPs encountered patients who believed that treatment involved a no-sugar diet. In contrast to HCPs perceptions, most patients stated to be aware of what carbohydrates are, and which products contained them. Patients believed that an unhealthy diet could result in hyperglycemia, cardiovascular diseases, weight gain and an increase of pharmacotherapy. Most HCPs stated that the majority of patients had insufficient knowledge regarding their pharmacotherapy. This manifested itself in not knowing which pills were glucose lowering pills, or being unfamiliar with their mode of action. HCPs indicated to make patients aware of the susceptibility of getting complications as a result of pharmacotherapy non-adherence [Quote \#14]. Most patients could not or only vaguely explain the mode of action of their medication. Almost all patients stated that non-adherence would result in hyperglycemia, and almost half of them associated non-adherence with long-term consequences like myocardial infarction, blindness, kidney problems and atherosclerosis. Some patients only using glucose lowering pills expressed the fear of non-adherence resulting in an increase of pharmacotherapy [Quote \#15].

\subsection{Motivational beliefs}

Near all HCPs and patients identified advantages of regular PA. In patients' perspective, frequently reported advantages were: feeling fitter, feeling more comfortable and energized, enjoying PA, and PA being good for their weight and glucose. Lowering their insulin use, decreasing the change of complications, and enjoying 
the social component of PA, were less frequently mentioned advantages. Near all patients and HCPs stated PA has no major disadvantages [Quote\#16]. Almost all patients identified advantages of a healthy diet. Having favorable blood glucose levels, feeling better, losing weight, and potentially decreasing their pharmacotherapy were most frequently mentioned advantages. Near all patients stated that a healthy diet doesn't involve disadvantages. Regarding adherence to pharmacotherapy, almost all patients reported its blood glucose lowering function as an advantage. Feeling healthier and believing pharmacotherapy controls T2DM, were other frequently mentioned advantageous beliefs. Most HCPs and patients indicated side effects, (fear of) hypoglycemia, feeling hungry, injection sites, weight gain, antipathy against introducing chemicals into their body, and social undesirability as disadvantages of pharmacotherapy adherence [Quote \#17].

Both HCPs and patients identified situations in which patients were perceived to have lower self-efficacy to adhere to their treatment strategies. Regarding PA adherence, lacking motivation, being busy, and feeling tired were most often mentioned situations. Less often mentioned situations were: if the weather is bad, when feeling ill or having to be physically active alone [Quote \#18]. Adherence to healthy diets is believed to be more difficult when: feeling tempted to eat unhealthy, feeling stresses, emotional or bored, having a party, and in weekends or evenings. These situations seem to provoke unhealthy snacking [Quote \#19]. Situations identified which might impede pharmacotherapy adherence were: being stressed, having a party, going out for diner, going on vacation, feeling ill, having an unstructured day/life, or in the evening. A single time, patients identified situations like: not feeling burdened by T2DM and their partner not alerting them as difficult situations [Quotes \#20 and \#21] (Table 3).

\section{Discussion and conclusion}

\subsection{Discussion}

The first aim of this study was to explore if and how treatment adherence success factors are applied in consultations between HCPs and patients. In our population, diabetes consultations usually took place quarterly, were highly protocolled, and included discussing treatment adherence. This is in line with current Dutch guidelines [36]. In line with HCPs' perceptions, most patients indicated not to prepare their consultations. Although HCPs pleaded for a more active contribution by their patients, few actually stimulated their patients to do so. HCPs and patients believed that decision making regarding consultation content and the formulation of treatment strategies was overall taking place in conjunction. However, a tendency towards reliance on HCPs' guidance was reported by HCPs as many patients, especially older patients, seemed to passively agree on HCPs' treatment suggestions. It is known that HCPs experience difficulties in involving patients in decision making [21]. Previous research showed that patients should be active collaborators in care, that HCPs should enable patients to make informed decisions, and that treatment decisions should preferably be made in conjunction [14,37]. Moreover, SDM should be at the center of diabetes consultations according to Dutch guidelines [36]. Applying SDM principles not only has the potential to improve quality of life, it has also been shown to improve physiological markers such as HbA1c-levels

Table 3

Interviewee quotes.

\begin{tabular}{|c|c|c|}
\hline $\begin{array}{l}\text { Quote } \\
\text { number }\end{array}$ & Respondent & Quote \\
\hline$\# 1$ & DN1 & $\begin{array}{l}\text { "If you don't plan it well concerning self-management, the consultation, there is a disproportion ... there are maybe } 10 \text { minutes to talk } \\
\text { about self-management . . . that is too short" }\end{array}$ \\
\hline \#2 & INT1 & "Some do [prepare], the majority doesn't. I think it accounts for most of our patients ... they just sit down and wait and see what happens" \\
\hline \#3 & T2DM3 & "They said: well, your sugar [level] should be better" \\
\hline \#4 & DN1 & $\begin{array}{l}\text { "Always small goals, very small steps, and also [to] approach it positively. You feel that works for people. If they would just not gain weight; } \\
\text { that is also ok" }\end{array}$ \\
\hline \#5 & PN1 & $\begin{array}{l}\text { "If I notice that they want to set too high goals of which I know they will never succeed in . . . than I will definitely say to them: well very } \\
\text { good that you thought about it, but maybe we should take smaller steps" }\end{array}$ \\
\hline \#6 & DN1 & $\begin{array}{l}\text { "You are a kind of team that tries to help each other; the patient helps you by giving information about their situation, and you try to help the } \\
\text { patient to gain control over their diabetes" }\end{array}$ \\
\hline \#7 & DIET2 & $\begin{array}{l}\text { "You often see in elderly, they say: "tell me what to do, what I should inject, what I should eat ... " following [advice] is not self- } \\
\text { management" }\end{array}$ \\
\hline \#8 & GP1 & “They know they should be physically active for 30-45 minutes daily, they know it, but they don't do it" \\
\hline \#9 & DN2 & "A cookie is a habit rather than exception, and the food is not limited to three meals daily" \\
\hline \#10 & T2DM11 & $\begin{array}{l}\text { "When it is } 3 \text { or } 4 \text { PM, I want to eat two cookies along with my coffee, or some licorices, and in the evening ... Once I start eating a couple of } \\
\text { sweets, than those taste buds . . . they keep asking for sugar" }\end{array}$ \\
\hline \#11 & DN2 & $\begin{array}{l}\text { "I think at least } 30 \% \text { doesn't always take that what they think they should do, definitely [there] are people who forget a pill, [and there] are } \\
\text { always people who purposely don't take their medication" }\end{array}$ \\
\hline \#12 & T2DM8 & $\begin{array}{l}\text { "In particular with insulin, kind of cheating we call it, by injecting a little more or a little less. Sometimes it works well, sometimes it goes } \\
\text { awfully wrong" }\end{array}$ \\
\hline \#13 & T2DM7 & $\begin{array}{l}\text { "I think I will gain some weight ... by expending more energy by being physically active, I can use less insulin, which makes me lose } \\
\text { weight" }\end{array}$ \\
\hline \#14 & INT1 & $\begin{array}{l}\text { "You try to motivate them by pointing at the complications ... that's the hardest part of diabetes, you don't give medication because people } \\
\text { suffer from complaints, unless they have hyperglycemia, but the approach is to invest in the future, to prevent a heart attack, blindness and } \\
\text { dialysis" }\end{array}$ \\
\hline \#15 & T2DM3 & "I get tired and off course a lot can happen to your blood vessels, [and] your eyes" \\
\hline \#16 & T2DM3 & "I think [you] become more physically fit, and your sugar [level] gets better . . and my weight will decrease" \\
\hline \#17 & T2DM7 & "I had abdominal pains, or [I was] nauseous of those pills, because I had to take a lot of them" [T2DM7] \\
\hline \#18 & GP1 & $\begin{array}{l}\text { "It can have various causes, that they don't understand it, or because they have no money, or they don't have time, or because it's really busy } \\
\text { at home, or because they feel ashamed, many different causes, or because they just don't feel like it" }\end{array}$ \\
\hline \#19 & DN2 & $\begin{array}{l}\text { "In between meals, and in the evening it happens even more, because mostly they had dinner and it's 7:30 PM, and then of course the closet } \\
\text { opens and people sit in front of the television . . . instead of doing some PA or walking, [they] snack, sometimes till late in the evening" }\end{array}$ \\
\hline \#20 & T2DM4 & "Everything involving distraction creates the chance to forget your pill" \\
\hline \#21 & DIET2 & "If you have a normal day, you'll take your pills. But if a day is really hectic . . . or they go out for dinner . . . then those pills are forgotten" \\
\hline
\end{tabular}


[38]. Although both HCPs and patients indicated that patients should be primarily responsible for treatment adherence, our results suggest that the $\mathrm{HCP}$ is the main initiator and responsible for making treatment decisions. This can have considerable unfavourable consequences for the execution of those strategies [38].

Contrary to perspectives of HCPs, most patients perceived that during consultations, no or not concrete enough treatment goals were set in order to manage their diabetes. Such perspective discrepancies between HCPs and patients might lead to not reaching treatment goals. As a consequence, nurses sometimes feel powerless if their patients do no reach treatment goals [21]. Earlier, the importance of applying goal setting principles in achieving behaviour change has been emphasised [39], and this approach has been shown to result in significant improvements in HbA1c-levels [40]. Although according to HCPs goal setting was applied, active patient engagement, clarity about goal setting, and adequate selfmanagement education on how to achieve those goals, seemed to be lacking. HCPs perceived that patients sometimes aimed for higher, unachievable goals. As a reaction, they indicated to tailor strategies to patients' abilities and proposed taking small steps in behaviour change. Despite these efforts of HCPs, it is known that many HCPs aren't trained to aid patients in setting achievable goals, and that they might lack knowledge in facilitating patients to set small goals or to make action plans [39]. In addition, HCPs might be willing to set goals for their patients themselves. While most HCPs and patients indicated to make treatment plans in conjunction, it seemed that especially older patients could be characterised as rather passive collaborators. Contrary to younger and more active patients, older patients should not only feel responsible for the execution of treatment strategies, but should also be actively involved in setting them. This leads to increased motivation and selfefficacy, and has positive consequences on its execution $[26,38,41]$. This is in particular of interest because HCPs reported that one reason for not reaching treatment goals in patients was a lack of motivation.

The second aim was to explore salient personal beliefs about T2DM treatment, including both healthy lifestyle adaptations and pharmacotherapy. First, this study indicated that adherence to the core diabetes treatment elements was suboptimal. HCPs emphasized that adherence was poor regarding all treatment elements, contrary to some patients who stated to adhere to one or more treatment elements. Both HCPs and patients felt that knowledge regarding PA was sufficient, however regarding knowledge of healthy diets, their perspectives differed: HCPs thought that this inadequate while patients thought that this was adequate. Regarding pharmacotherapy, both groups reported that patients' knowledge was insufficient. Many patients were aware of the susceptibility of getting complications as a result of non-adherence to core treatment elements, although most of these were shortterm consequences. It is notable that despite the reported poor adherence, many advantageous beliefs were reported of adherence to all treatment elements. Contrary to PA and healthy diets, pharmacotherapy adherence also yielded many disadvantages. Larkin et al. [42] reported that in particular non-adherent patients were more likely to be worried about pharmacological side effects. Disadvantages like these are frequently reported regarding taking oral medication [43], should be thoroughly discussed in consultations, and patients should be made aware that the advantages of adherence outweigh the disadvantages [26]. Last, self-efficacy to adhere to treatment strategies seemed to be lower in certain difficult situations, which tend to occur when daily routine is compromised, like having an unstructured day/life. Similar difficult situations were reported for PA, healthy diets and pharmacotherapy. Low self-efficacy has been related to reduced adherence levels earlier [44], and should therefore be enhanced, especially in these situations out of daily routine.

This study shows some strengths and limitations. First, HCPs and patients were interviewed, allowing comparison of both perspectives. Second, a theoretical framework (The I-Change Model) was used which incorporates factors that are known to determine behaviours involved in diabetes treatment. These factors were operationalized to contribute to a better understanding of the underlying salient beliefs. Last, our data was analyzed systematically using a deductive coding approach with a predefined coding tree. Our analysis showed satisfying intercoder reliability and agreement levels. This study also has some limitations. First, participants were recruited from one geographical region. Recruitment of HCPs proved to be more difficult than expected as just one internist was recruited. Despite efforts to create sample heterogeneity, future studies should aim for nationwide recruitment to increase generalizability. Second, some interviews were split in two parts because of patients' time restraints. Future interviews should possibly be more concise and set time limits. Third, post-motivational determinants like action planning and coping planning should also receive attention in terms of identifying salient personal beliefs regarding these determinants. Last, the qualitative design of the study yielded in-depth findings, but observational research designs are required to objectively assess our findings.

\subsection{Conclusion}

Our T2DM patient sample shows insufficient metabolic control and both perspectives of HCPs and patients add up to the conclusion that both lifestyle and medication adherence is suboptimal. Most patients visited their consultations unprepared, justified by perspectives of both interviewed groups. Patients did not or only vaguely experience that treatment goals were set, whereas HCPs indicated to actually provide them. Although both groups believed that SDM is applied, it seemed a rather passive collaboration, with the HCP mostly in charge of making treatment decisions. However, contrary to older patients, younger patients could actually be characterised as more active collaborators. A lack of motivation and inactive involvement of patients might justify poor treatment adherence. Also the inability of HCPs to involve patients in decision making, the potential incapacity of HCPs to set achievable goals for their patients, and the misconception between HCPs and patients about if goals are actually set, could contribute to poor treatment adherence. Regarding personal beliefs, awareness factors seemed to be sufficient. However, perspectives regarding healthy nutrition knowledge of patients, differed between HCPs and patients, and pharmacotherapy knowledge and awareness of long-term consequences could be improved. Despite reporting many advantages of treatment adherence, and excluding pharmacotherapy - few disadvantages, treatment adherence was still suboptimal. As indicated by HCPs and patients, self-efficacy seemed to be lower in situations outside daily routine, and should be enhanced to improve treatment adherence.

\subsection{Practice implications}

A fruitful collaboration between HCPs and T2DM patients should build on input and active engagement from both parties. Shared-agreement and clarity about goals, taking small steps in behaviour change, and tailoring goals to patients' needs and abilities are considered key factors in facilitating treatment adherence. HCPs should make patients aware that they should also be responsible for active preparation, engagement and collaboration in the formation of treatment strategies. Self- 
management education, accompanied by use of salient personal beliefs about T2DM treatment, should be cornerstone of consultations. These can enhance the necessary motivation for improving treatment adherence, support adequate self-management, and facilitate persisted behaviour change outside consultation time.

\section{Conflicts of interest}

None declared.

\section{Informed consent and patient details}

The authors confirm all patient/personal identifiers have been removed or disguised so the patient/person(s) described are not identifiable and cannot be identified through the details of the story.

\section{Acknowledgements}

This work was supported by the MUMC+ Strategy 2020. The funding source had no involvement in preparing or conducting the research or research article. The authors would like to thank Anuska Muyres for assisting in coding the interviews, and Yil Severijns and Kenny Curfs for transcribing the interviews.

\section{References}

[1] RIVM, Nationaal Kompas Volksgezondheid, versie 4.17: Diabetes Mellitus, (2014) . Available from: http://www.nationaalkompas.nl/gezondheid-enziekte/ziekten-en-aandoeningen/endocriene-voedings-enstofwisselingsziekten-en-immuniteitsstoornissen/diabetes-mellitus/.

[2] Federation ID. Diabetes Atlas, sixth edition, (2013) . Available from: http:// www.idf.org/sites/default/files/EN_6E_Atlas_Full_0.pdf.

[3] B.A. Swinburn, G. Sacks, K.D. Hall, K. McPherson, D.T. Finegood, M.L. Moodie, et al., The global obesity pandemic: shaped by global drivers and local environments, Lancet 378 (9793) (2011) 804-814.

[4] S. Newman, L. Steed, K. Mulligan, Chronic Physical Illness: Self-management and Behavioural Inteventions, Open University Press, Maidenhead, 2009.

[5] R.R. Holman, S.K. Paul, M.A. Bethel, D.R. Matthews, H.A. Neil, 10-year follow-up of intensive glucose control in type 2 diabetes, N. Engl. J. Med. 359 (15) (2008) 1577-1589.

[6] S. Vijan, N.S. Stuart, J.T. Fitzgerald, D.L. Ronis, R.A. Hayward, S. Slater, et al., Barriers to following dietary recommendations in Type 2 diabetes, Diabet. Med. 22 (1) (2005) 32-38.

[7] R.R. Rubin, Adherence to pharmacologic therapy in patients with type 2 diabetes mellitus, Am. J. Med. 118 (Suppl. 5A) (2005) 27S-34S.

[8] J.A. Cramer, A systematic review of adherence with medications for diabetes, Diabetes Care 27 (5) (2004) 1218-1224.

[9] K.M. Nelson, G. Reiber, E.J. Boyko, I.I.I. Nhanes, Diet and exercise among adults with type 2 diabetes: findings from the third national health and nutrition examination survey (NHANES III), Diabetes Care 25 (10) (2002) 1722-1788.

[10] E.H. Morrato, J.O. Hill, H.R. Wyatt, V. Ghushchyan, P.W. Sullivan, Physical activity in U.S. adults with diabetes and at risk for developing diabetes, 2003, Diabetes Care 30 (2) (2007) 203-209.

[11] D.E. King, A.G. Mainous 3rd, M. Carnemolla, C.J. Everett, Adherence to healthy lifestyle habits in US adults, 1988-2006, Am. J. Med. 122 (6) (2009) 528-534.

[12] I. Krass, P. Schieback, T. Dhippayom, Adherence to diabetes medication: a systematic review, Diabet. Med. 32 (6) (2015) 725-737.

[13] E. van't Riet, M.T. Schram, E.J. Abbink, W.M. Admiraal, M.W. Dijk-Schaap, F. Holleman, et al., The diabetes pearl: diabetes biobanking in The Netherlands, BMC Public Health 12 (2012) 949.

[14] M.M. Funnell, R.M. Anderson, Empowerment and self-management of diabetes, Clin. Diabetes 22 (3) (2004) 123-127.

[15] C. Asche, J. LaFleur, C. Conner, A review of diabetes treatment adherence and the association with clinical and economic outcomes, Clin. Ther. 33 (1) (2011) 74-109.

[16] P.M. Ho, J.S. Rumsfeld, F.A. Masoudi, D.L. McClure, M.E. Plomondon, J.F. Steiner, et al., Effect of medication nonadherence on hospitalization and mortality among patients with diabetes mellitus, Arch. Intern. Med. 166 (17) (2006) 1836-1841.
[17] D. Lorber, Importance of cardiovascular disease risk management in patients with type 2 diabetes mellitus, Diabetes Metab. Syndr. Obes.: Targets Ther. 7 (2014) 169-183.

[18] E.L. Barr, P.Z.Zimmet, T.A. Welborn, D. Jolley, D.J. Magliano, D.W. Dunstan, et al., Risk of cardiovascular and all-cause mortality in individuals with diabetes mellitus, impaired fasting glucose, and impaired glucose tolerance: the Australian Diabetes, Obesity, and Lifestyle Study (AusDiab), Circulation 116 (2) (2007) 151-157.

[19] I.M. Stratton, A.I. Adler, H.A. Neil, D.R. Matthews, S.E. Manley, C.A. Cull, et al., Association of glycaemia with macrovascular and microvascular complications of type 2 diabetes (UKPDS 35): prospective observational study, BMJ 321 (7258) (2000) 405-412.

[20] E.H. Wagner, B.T. Austin, C. Davis, M. Hindmarsh, J. Schaefer, A. Bonomi, Improving chronic illness care: translating evidence into action, Health Aff. (Millwood) 20 (6) (2001) 64-78.

[21] R. Jansink, J. Braspenning, T. van der Weijden, G. Elwyn, R. Grol, Primary care nurses struggle with lifestyle counseling in diabetes care: a qualitative analysis, BMC Fam. Pract. 11 (2010) 41.

[22] J. Jarvis, T.C. Skinner, M.E. Carey, M.J. Davies, How can structured selfmanagement patient education improve outcomes in people with type 2 diabetes? Diabetes Obes. Metab. 12 (1) (2010) 12-19.

[23] N.D. Federatie, De NDF Zorgstandaard diabetes Type 2 volwassenen, (2013). Available from: http://www.zorgstandaarddiabetes.nl/type-2/.

[24] D.P. French, A.N. Wade, A.J. Farmer, Predicting self-care behaviours of patients with type 2 diabetes: the importance of beliefs about behaviour, not just beliefs about illness, J. Psychosom. Res. 74 (4) (2013) 327-333.

[25] L.E. Garcia-Perez, M. Alvarez, T. Dilla, V. Gil-Guillen, D. Orozco-Beltran, Adherence to therapies in patients with type 2 diabetes, Diabetes Ther: Res. Treat. Educ. Diabetes Relat. Disord. 4 (2) (2013) 175-194.

[26] A.M. Delamater, Improving patient adherence, Clin. Diabetes 24 (2006) 71-77.

[27] J.J. Francis, M. Johnston, C. Robertson, L. Glidewell, V. Entwistle, M.P. Eccles, et al., What is an adequate sample size? Operationalising data saturation for theory-based interview studies, Psychol. Health 25 (10) (2010) 1229-1245.

[28] H. Vries, I. Mesters, H. van de Steeg, C. Honing, The general public's information needs and perceptions regarding hereditary cancer: an application of the Integrated Change Model, Patient Educ. Couns. 56 (2) (2005) 154-165.

[29] I. Ajzen, The theory of planned behavior, Organ. Behav. Hum. Decis. Process. 50 (1991) 179-211.

[30] N.K. Janz, M.H. Becker, The health belief model: a decade later, Health Educ. Q. 11 (1) (1984) 1-47.

[31] J.O. Prochaska, C.C. DiClemente, Stages and processes of self-change of smoking: toward an integrative model of change, J. Consult. Clin. Psychol. 51 (3) (1983) 390-395.

[32] H. de Vries, I. Mesters, J.V. Riet, K. Willems, A. Reubsaet, Motives of Belgian adolescents for using sunscreen: the role of action plans, Cancer Epidemiol. Biomarkers Prev. 15 (7) (2006) 1360-1366.

[33] NVivo Qualitative Data Analysis Software, QSR International Pty Ltd., 2012 Version 10.

[34] D. Mortelmans, Kwalitatieve Analyse Met Nvivo, Acco, Leuven/Den Haag, 2011.

[35] D.G. Altman, Practical Statistics for Medical Research, Chapman \& Hall/CRC, London, 1991.

[36] N.D. Federatie, NDF Zorgstandaard Diabetes Type 2 Volwassenen, (2013) Available from: http://www.zorgstandaarddiabetes.nl/wp-content/uploads/ 2015/08/NDF-Zorgstandaard-diabetes-type-2-Volwassenen-2015.pdf.

[37] S.E. Inzucchi, R.M. Bergenstal, J.B. Buse, M. Diamant, E. Ferrannini, M. Nauck, et al., Management of hyperglycaemia in type 2 diabetes: a patient-centered approach. Position statement of the American Diabetes Association (ADA) and the European Association for the Study of Diabetes (EASD), Diabetologia 55 (6) (2012) 1577-1596.

[38] V.M. Montori, A. Gafni, C. Charles, A shared treatment decision-making approach between patients with chronic conditions and their clinicians: the case of diabetes, Health Expect. 9 (1) (2006) 25-36.

[39] D.A. DeWalt, T.C. Davis, A.S. Wallace, H.K. Seligman, B. Bryant-Shilliday, C.L. Arnold, et al., Goal setting in diabetes self-management: taking the baby steps to success, Patient Educ. Couns. 77 (2) (2009) 218-223.

[40] A.D. Naik, N. Palmer, N.J. Petersen, R.L. Street Jr., R. Rao, M. Suarez-Almazor et al., Comparative effectiveness of goal setting in diabetes mellitus group clinics: randomized clinical trial, Arch. Intern. Med. 171 (5) (2011) 453-459.

[41] M. Heisler, S. Vijan, R.M. Anderson, P.A. Ubel, S.J. Bernstein, T.P. Hofer, When do patients and their physicians agree on diabetes treatment goals and strategies, and what difference does it make? J. Gen. Intern. Med. 18 (11) (2003) 893-902.

[42] A.T. Larkin, C. Hoffman, A. Stevens, A. Douglas, Z. Bloomgarden, Determinants of adherence to diabetes treatment, J. Diabetes 7 (6) (2015) 864-871.

[43] J. McSharry, L. McGowan, A.J. Farmer, D.P. French, Perceptions and experiences of taking oral medications for the treatment of Type 2 diabetes mellitus: a systematic review and meta-synthesis of qualitative studies, Diabet. Med. 33 (10) (2016) 1330-1338.

[44] M. Mishali, H. Omer, A.D. Heymann, The importance of measuring self-efficacy in patients with diabetes, Fam. Pract. 28 (1) (2011) 82-87. 